\title{
Pueblo, comunidad y mito en Juan Moreira de Leonardo Favio y en Facundo. La sombra del Tigre de Nicolás Sarquís
}

\section{Suárez, Nicolás}

Resumen:

El trabajo aborda dos transposiciones de textos de la literatura argentina del siglo XIX que fueron llevados al cine en el último tercio del siglo XX: Juan Moreira (Leonardo Favio, 1973) y Facundo. La sombra del tigre (Nicolás Sarquís, 1995). A partir de la inscripción de ambos films en sus respectivos contextos históricopolíticos, se apunta a contrastar los modelos comunitarios que emanan de cada una de las obras, así como las figuraciones de los conceptos de pueblo y mito que ellas proponen.

Palabras clave:

pueblo - comunidad - mito - literatura argentina - cine argentino.
Cuadernos del Centro de Estudios de Diseño y Comunicación № 61

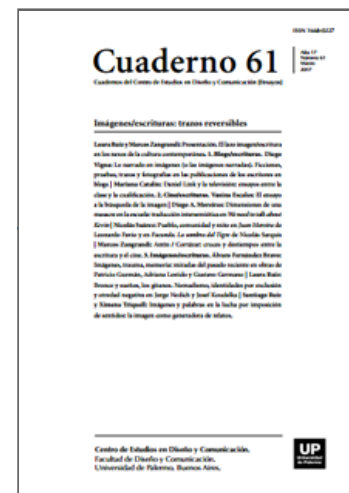

ISSN: 1668-0227

Imágenes/escrituras:

trazos reversibles

Año XVII, Marzo 2017, Buenos Aires, Argentina | 176 páginas

descargar PDF ver índice de la publicación

Ver todos los libros de la publicación

compartir en Facebook

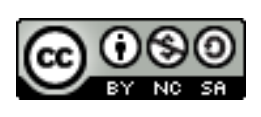

Esta obra está bajo una Licencia Creative

Commons Atribución-NoComercialCompartirlgual 4.0 Internacional

(*) Licenciado en Letras por la Universidad de Buenos Aires. Adscripto a la cátedra Literatura Argentina I de la misma universidad. Guionista cinematográfico recibido en la Escuela Nacional de Experimentación y Realización Cinematográfica (ENERC). Doctorando en Letras con un proyecto sobre las transposiciones cinematográficas de textos de la literatura argentina del siglo XIX. Becario de CONICET.

En el año 1972, cuando filmaba en La Rioja La muerte de Sebastián Arache y su pobre entierro, Nicolás Sarquís tuvo la idea de realizar un filme sobre la vida de Facundo Quiroga.

El proyecto, acicateado por el gobernador de La Rioja Carlos Menem, comenzó a filmarse en 1976, pero el rodaje fue rápidamente interrumpido a causa del golpe militar. Por su parte, también en 1972, Leonardo Favio se encontraba en pleno rodaje de su Juan Moreira, primera incursión en el cine masivo del popular cantante que, en su faceta de cineasta, se había caracterizado hasta ese momento por desarrollar una obra marcadamente minimalista. 
La película se estrenó el 24 de mayo de 1973, un día antes de que Héctor José Cámpora y Carlos Menem asumieran la presidencia de la nación y la gobernación de La Rioja, respectivamente, como parte de una misma renovación política que anticipaba el retorno de Juan Perón a la Argentina. Más de veinte años después, los destinos políticos y cinematográficos de Favio y Sarquís volverían a cruzarse. En el año 1995, Sarquís estrenó Facundo. La sombra del tigre con el decidido apoyo de Menem que, entonces, se preparaba para ser reelecto como presidente de los argentinos luego de una polémica reforma constitucional.

Ese mismo año, Favio había proyectado estrenar una película pensada como homenaje por el quincuagésimo aniversario del 17 de octubre de 1945 que, finalmente, vería la luz en 1999, con el título de Perón, sinfonía del sentimiento.

¿Cómo pensar este rizo que, en un doble vaivén, nos lleva del siglo XX al XIX y de la década de 1970 a la de 1990? A este respecto, además de la conocida filiación política de ambos directores, resulta significativa la inscripción contextual de los filmes, que fueron estrenados en momentos en que el peronismo buscaba ampliar su legitimidad política. Para abordar estas cuestiones, quisiera partir de la idea de que las películas de Favio y Sarquís sobre las vidas de Juan Moreira y Facundo Quiroga postulan una imagen del peronismo como una experiencia comunitaria cuyo mito de origen funciona como prueba de legitimidad política, en tanto cuenta la historia pasada del pueblo que está creando.

Para avanzar en esta dirección, trataré de articular las diversas elaboraciones del mito que surgen de cada película con diferentes modelos comunitarios, en el marco de una lucha simbólica por la formación de una argentinidad que concibo, según los planteos de Benedict Anderson (2011), como una comunidad imaginada. La noción de comunidad, sin embargo, no será abordada en base al sentido de soberanía que adquiere en los planteos de Anderson sino desde la perspectiva biopolítica que, primero en Francia y luego en Italia, fue introducida por filósofos como Jean-Luc Nancy, Maurice Blanchot, Jacques Derrida, Giorgio Agamben y Roberto Esposito. A raíz del fracaso de los totalitarismos del siglo XX, estos autores plantearon la necesidad de repensar la pregunta por la comunidad. Como apunta Jean-Luc Nancy, el hecho de que la más grande obra de muerte de la humanidad se haya llevado a cabo en nombre de la comunidad es lo que ha puesto fin a toda posibilidad de basarse sobre cualquier forma de lo dado del ser común (2000, p. 17). Esta nueva tarea del pensamiento comunitario adopta en la obra de Nancy inflexiones que, por su modo de indagar la relación entre comunidad y mito, resultan pertinentes para el presente trabajo.

En su libro La comunidad inoperante, Nancy sostiene que, entre mito y comunidad, existe una relación de reciprocidad tal que no hay mito sin comunidad ni comunidad sin mito (2000, p. 86). De ahí que, una vez interrumpida la voz de la comunidad absoluta, lo que queda es la voz de la "comunidad del mito interrumpido", en la que el relato unívoco del origen y destino de la comunidad se ve interrumpido por el propio mito (p. 97). A lo largo de estas páginas y tomando en consideración este renacimiento del interés comunitario, intentaré realizar una lectura de las transposiciones cinematográficas de Facundo, de Domingo Sarmiento, y Juan Moreira, de Eduardo Gutiérrez, que Leonardo Favio y Nicolás Sarquís llevaron a cabo en las últimas décadas del siglo XX. 
Hay una imagen que quisiera tomar como puerta de entrada a la historia de las relaciones imaginarias entre Moreira y Perón. Dicha imagen exige remontarnos a una crónica sobre la muerte de Moreira que Fray Mocho publicó en Caras y Caretas el 4 de abril de 1903, con el seudónimo de Fabio Carrizo. Entre los diversos documentos que ilustran la nota, hay una fotografía del famoso cráneo de Moreira con un epígrafe que dice: "El cráneo de Moreira conservado por la señora Dominga D. de Perón, viuda del doctor Tomás Perón”.

Esta información debe completarse con un dato que brinda Josefina Ludmer en el capítulo de El cuerpo del delito titulado "Los Moreira": Dominga D. es Dominga Dutey, madre de Mario Tomás Perón y abuela de Juan Domingo (Ludmer, 2011, p. 292). A partir de estos documentos, podemos, pues, fantasear una escena imaginaria cuya veracidad importa menos que su verosimilitud: el niño Juan Domingo, de apenas siete años de edad, merodea por la casa de su abuela y toma juguetonamente entre sus manos el cráneo del mítico Juan Moreira. ¿Qué aportaría esta boutade a las relaciones entre Moreira y Perón? ¿Qué zonas de la película de Favio permitiría iluminar? Se trata, creo, de algo más que la constatación de un relevo (Perón nace, en efecto, allí donde muere Moreira: en el pueblo de Lobos). Hay, evidentemente, algo del orden de lo corporal que este encuentro pone en juego. Pero también algo del orden de lo político: el encuentro entre Moreira y Perón a comienzos del siglo XX supone, al igual que en la película de Favio, el encuentro entre dos figuras populares que son asimismo dos significantes vacíos1. Por un lado, como señala Juan Pablo Dabove en la senda trazada por el señero estudio de Adolfo Prieto (2006), gracias a la desterritorialización operada por Eduardo Gutiérrez, desde fines del siglo XIX el gaucho malo se convirtió en un significante vacío que opera con una labilidad política máxima, una metáfora de conflicto e integración a la vez, que sirvió para la coagulación de algo como un "sujeto popular" (Dabove, 2010, pp. 307-313). Por su parte, durante las décadas de 1960 y 1970, según lo ha demostrado Ernesto Laclau, la demanda del regreso de Perón a la Argentina se convirtió en el significante unificador de un campo popular en expansión (Laclau, 2005, p. 269). Aquí es donde cobra relevancia la dimensión corporal del encuentro entre Moreira y Perón, en tanto metáfora organicista que asocia el orden social a la depuración de un cuerpo enfermo. En palabras del propio Perón: "Las masas sienten y valen por sus conductores; son como un músculo dirigido por un centro cerebral" (1971, p. 141).

Esta sería una posible lectura de la película de Favio. Su Moreira sería (como en las escenas de rebelión popular que abren y cierran el relato) una suerte de centro cerebral de las masas de espectadores. Dichas masas, que acudieron a las salas batiendo récords de espectadores, son las mismas que el día después del estreno se manifestaron en la Plaza de Mayo para celebrar la inminente llegada de Perón. Sin embargo, como afirma Laclau, la unidad de un pueblo constituido de esa manera era extremadamente frágil (2005, p. 270). El filme de Favio se inscribe justamente en ese momento límite en que Perón deja de ser un significante vacío y, próximo a ocupar la presidencia, empieza a verse obligado a tomar decisiones y optar por alternativas. Esto habilita una segunda lectura de la película, que problematiza la primera. Según esta perspectiva, lo que interesa no es solo la película como mecanismo para encuadrar u organizar a la masa, sino también el concepto de cuadro en su sentido cinematográfico, es decir, como aquello que se corresponde con los límites físicos de la imagen. Si tenemos en cuenta que en 1973 la figura de Juan Moreira ya había sido llevada cuatro veces al cine, esta cuestión debe haber tenido cierta importancia para Favio: ¿cómo encuadrar a Moreira? Desde el punto de vista de la conducción política, la apropiación peronista de Moreira no agotaría la productividad del héroe, ya que la figura adecuada para aprehenderlo no sería la del centro cerebral sino más bien la de algo que, lejos de la metáfora organicista del Pueblo-Uno, se aproximaría a la idea de un Cuerpo sin Órganosdeleuzeano2. Frente a la cristalización de la Comunidad Organizada en el líder, pues, el cuerpo desmembrado o desorganizado de 
Moreira viene a evidenciar que en la película de Favio hay algo del orden de lo mítico que desborda el concepto de cuadro entendido en su acepción política.

Precisamente, para dar cuenta de esto, Favio apela al manejo del encuadre cinematográfico como un recurso fundamental para la mitologización de la figura de Moreira. Los juegos con las alturas de cámara permiten elevar o rebajar a los personajes según las necesidades dramáticas. Así, por ejemplo, en el final, mientras Moreira permanece encerrado en la habitación se lo registra mayormente en planos cenitales, pero cuando sale a enfrentar a la partida se recurre a planos contrapicados que destacan su carácter heroico. El uso de los tamaños de planos, por su parte, funciona en este mismo sentido enaltecedor.

Si los primeros planos adoptan -gracias a los contrastes de luz y sombra, al brillo en la mirada, al empleo del contraluz y del efecto flou- un aura mística, el tratamiento barroco de los cielos carga de religiosidad a los planos generales. La relación entre estos dos tipos de planos a menudo se establece mediante el uso de zooms violentos típicos del western, que permiten integrar a los personajes al medio en el que habitan. Del mismo modo, los travellings circulares alrededor de los personajes construyen, mediante un enrarecimiento del espacio, una cosmovisión cíclica, no lineal. De esta manera, desde el encuadre mismo, la figura de Moreira parece asumir, tal como apuntan Gonzalo Aguilar y David Oubiña, las características de un mito, en tanto encarnación individual del pensamiento de un pueblo (1993, p. 88).

Pero ¿qué rasgos adopta en el filme ese pueblo que el mito de Moreira viene a encarnar? Mi hipótesis es que la película de Favio funciona como una experiencia comunitaria que apela a un pasado mitológico para postular una comunidad de los ausentes, en la que el mito de Moreira se conecta tanto con la imagen de un pueblo entonces apartado del juego democrático como con la imagen de Perón, el gran ausente.

La articulación entre mito y pueblo se advierte ya en los primeros planos de la película. La propia estructura circular del relato, que se abre con un levantamiento popular en nombre de la memoria de Moreira y se cierra con su muerte, estaría marcando la idea de supervivencia mítica del héroe y de una temporalidad que no es cronológica sino que va en contra de la historia. Pero la identificación del pueblo con la figura de Moreira no es actual sino que está mediada por una ausencia. El “¡Viva Juan Moreira, mierda!” que abre la película ocurre justamente en la escena del entierro, lo cual implica que el reconocimiento hacia el héroe solo se da post mortem. Antes de eso, los paisanos, más bien, parecen temerle a Moreira por sus bravatas y arrebatos violentos. Y si en la escena del mercado vemos a una anciana que exhibe ante un pequeño auditorio una serie de imágenes alusivas a la vida de Moreira, el reconocimiento que involucra esta voz popular supone también una falta, ya que Moreira "con mil partidas peleó y hoy en la pampa se oculta".

Esta condición ausente del héroe en tanto encarnación del pueblo es la razón por la cual, de todos los Moreira que ha dado el cine nacional, el de Favio es el más moderno. En términos de Deleuze, porque no se dirige a un pueblo supuesto, ya ahí, sino que contribuye a la invención de un pueblo que falta (2005, p. 288). En esto radica, por ejemplo, la distancia respecto de la versión cinematográfica de Luis José Moglia Barth, del año 1948. En esta versión, la propia capacidad que tiene Moreira de movilizar a las masas es signo de su clasicidad, puesto que el pueblo "está ya ahí, real antes de ser actual, ideal sin ser abstracto" (Deleuze, 2005, p. 286). En cambio, Favio, que en los sesenta había pasado por la experiencia de la vanguardia, logra superar la rigidez del modelo criollista industrial e incorpora la ambigüedad como elemento dinámico de la historia, para producir la fabulación de un pueblo que vendrá. 
De esta manera, si el olvido de los compromisos de Moreira con el Estado había sido la condición de posibilidad para su heroización (Dabove, 2010, p. 315), la película de 1973 recupera y explota la ambigüedad de esa imagen de un Moreira atravesado -en sus propias palabras- "por esta vergüenza mía de verme sucio, sucio y tan culpable de algo que no comprendo". Pero la diferencia con el Moreira de Gutiérrez radica en que este es incapaz de constituirse en comunidad. Como indica Dabove, el levantamiento antiestatal del pueblo en nombre de la memoria de Moreira no ocurriría nunca en las novelas de Gutiérrez, cuyos gauchos malos difícilmente puedan considerarse modelos a seguir (2010, p. 303).

También Aguilar (2011) detecta el carácter problemático de la construcción del pueblo en la película, cuando señala que este se articula en torno a una contradicción: cómo puede un héroe popular ser también cruel, despiadado y, en ciertas ocasiones, servil. Al exponer la contradicción de un héroe popular que es a la vez un puntero político, entonces, Favio estaría señalando el lugar fallado de la comunidad.

Esta inflexión singular que Favio imprime al mito de Moreira se hace notoria si se piensa en uno de los cambios argumentales más significativos que la película introduce con respecto a la novela. En contraste con lo que ocurre en el texto de Gutiérrez en el que, ante los abusos del teniente alcalde, Vicenta decide amancebarse con el compadre Giménez para asegurar la subsistencia de Juancito (1999, p. 158), en el filme el hijo de Moreira muere de viruela luego de que este venciera a la Muerte en una partida de truco. La muerte de Juancito, por lo tanto, puede pensarse como un filicidio involuntario que, en el momento mismo de la violencia política en Argentina, da cuenta de la constitución problemática del pueblo: Moreira es el héroe popular que no tiene herederos o, mejor, estos se hacen presentes por su ausencia. Siguiendo los planteos de Roberto Esposito, diríamos que la comunidad lleva dentro de sí un don de muerte que amenaza la integridad de los sujetos que relaciona y que, como en Nazareno Cruz y el lobo (1975), adopta la forma del asesinato de los propios hijos. En esta película que, junto con Juan Moreira, marca en la obra de Favio el pasaje del cine intimista de los años sesenta hacia uno masivo, el padre de Griselda, sin quererlo, conduce al pueblo hacia el asesinato de su hija. Es decir, como apunta Gonzalo Aguilar (2012a), que la no aceptación de la propia extrañeza acaba llevando a la comunidad hacia el acto más bestial: el filicidio.

Este problema vuelve a aparecer en agosto de 1994, más de dos décadas después del estreno de la versión de Favio, en la obra de teatro Juan Moreira, el argentino, de Gerardo Pensavalle. En este caso, Juancito es secuestrado y llevado al convento por don Francisco que, además, asesina a Vicenta. Las autoridades que combaten a Moreira, en tanto, son los "milicos" (Zayas de Lima, 2010, pp. 27-28). Luego de la dictadura más sangrienta de la historia argentina, la vuelta del héroe se resignifica. El filicidio es ahora el de una sociedad cuyos hijos desaparecen. En 1994 no solo se cumplían veintiún años del Juan Moreira de Favio, sino que también se cumplían veintiún años del nacimiento de Omar Carrasco, el joven que en marzo del mismo año había sido desaparecido mientras realizaba el servicio militar, en un caso de enormes repercusiones mediáticas que pronto desembocarían en la revocación del servicio militar obligatorio. Al igual que la película de Favio, entonces, la obra de Pensavalle actualiza la politicidad del mito de Moreira como símbolo del gaucho perseguido por la justicia. Pero la coyuntura es otra. Ya no se trata del contexto de violencia política de los setenta y ese cambio incide en las condiciones de circulación. La radicalización de los procesos de modernización cultural y la politización de la vida cotidiana que en los setenta habían posibilitado la emergencia del Juan Moreira de Favio como un concentrado con altas dosis de politicidad y masividad, enseguida dejarían de operar. 
Desde finales de la década de 1970, la fórmula que determina la circulación de los Moreira en la cultura argentina podría enunciarse de la siguiente manera: a mayor politicidad, menor masividad (y viceversa). Así, en 1980 Alberto Olmedo solo puede representar a Juan Moreira en su programa televisivo al precio de despolitizarlo3, de la misma manera que, en 1994, Pensavalle actualiza la politicidad del texto teatral pero debe hacerlo como una puesta independiente en el teatro El Colonial y en algunas plazas porteñas4. Como parte de este mismo proceso, ya en 1995, apenas unos meses después de la presentación de la obra de Pensavalle, el Moreira de Favio reaparece en un nuevo soporte. La película acompañaba en forma de video la revista Página30, publicación mensual de la cultura progresista. Para decirlo con Ludmer, el héroe violento que no tiene descendientes reaparecía precisamente en el momento en que liberalismo, peronismo y Estado eran lo mismo (1998, p. 14).

1995

En ese momento, mientras Moreira perdía masividad, otro mito decimonónico ganaba terreno en la cultura argentina. Tras filmar el documental Menem. Retrato de un hombre, en 1990 Nicolás Sarquís retoma su proyecto sobre la vida de Facundo Quiroga con el doble objetivo de crear una miniserie de cuatro capítulos de cincuenta minutos cada uno y un largometraje de dos horas de duración para su proyección en salas de cine. La película, estrenada en 1995, se llamó Facundo. La sombra del Tigre y contó con el apoyo financiero del canal estatal Argentina Televisora Color (ATC), el Instituto Nacional de Cine y Artes Audiovisuales (INCAA), la Subsecretaría de la Nación y la Fundación para el Desarrollo de Temas Audiovisuales (Neifert, 2012, p. 299).

Ya desde el título, Facundo. La sombra del Tigre revela una relación problemática con el texto de Sarmiento que, sin embargo, no se corrobora ni en los créditos ni en la película misma. El filme pretende ser una lectura crítica de Facundo pero esta resulta fallida por sus propias inconsistencias. Para un abordaje de estas cuestiones, quisiera proponer que, así como en el caso de Favio se trata de la comunidad de los ausentes, el modelo comunitario rastreable en la película de Sarquís puede pensarse a partir del concepto aristotélico de philia. Según se desprende de los últimos libros de la Ética Nicomáquea, la noción de philia guarda una estrecha relación con la de polis. Esta última, también llamada "comunidad política", constituye un todo orgánico que contiene diversas formas de vida en común (koinonía), entre las cuales se encuentran la casa (oîkos) o la aldea, pero cuya especie paradigmática recibe el nombre de amistad o philia. La philia, así, aludiría a la relación afectiva entre los hombres que funciona como modelo ético de la polis (Álvaro, 2013, p. 160).

Este tipo de relación opera tanto en las condiciones de producción como en el discurso mismo del filme. En relación con el primero de estos aspectos, José Pablo Feinmann, guionista de la película, parece apelar a la philia como estrategia para desmarcarse de las vinculaciones del proyecto con el menemismo. En una entrevista concedida diez años después del lanzamiento del filme, declara: Lo que pasa es que [la película] se contaminó con el menemismo porque Nicolás era muy amigo de Menem. Entonces yo me peleé con él, no fui al estreno. [...] Lo que hay que entender es que ellos eran amigos de la infancia, jugaban juntos.

(Cuman y Sierra, 2005, p. 119) Feinmann pretende justificar el evidente carácter menemista de la obra por la existencia previa de un vínculo entre "pibes", como si la philia no fuera también un modo de construir lo político y una decisión estética de la que él mismo participó. Porque la philia emerge justamente en la parte del guión que fue escrita por Feinmann: el viaje de Facundo y su secretario Santos Ortiz en la galera. Las extensas conversaciones entre ambos y el carácter amistoso de las mismas dan cuenta del privilegio que la película 
otorga a Santos Ortiz como modelo de intelectual en detrimento de la figura de Alberdi, que aparece trivializada en la primera parte de la historia (escrita por Roberto Scheuer, el otro guionista). Asimismo, las lecturas y debates constantes entre Quiroga y Santos Ortiz en torno a la novela Viaje del Joven Anacarsis, escrita por Jean-Jacques Barthélemy (1847), vienen a reforzar esta reivindicación de la philia como modelo de vida, en tanto concepto premoderno de comunidad, anterior a la diferenciación entre comunidad y sociedad5 trazada por las ciencias sociales en el siglo XIX como crítica al racionalismo imperante.

Ya el propio Sarmiento, en las primeras páginas de Facundo, se hacía eco de esta tensión entre comunidad y sociedad, en el mismo momento en que el problema empezaba a ser formulado con fuerza en el ámbito de las letras europeas6. En el capítulo titulado "Asociación - La pulpería”, ante la "falta de verdadera sociedad" (2006, p. 63) en que vive el campesino, Sarmiento consigna la necesidad de "una sociedad ficticia para remediar esta desasociación normal" (p. 64). No sorprende, entonces, que el modelo comunitario que el sanjuanino opone a este "género de asociación monstruoso" sea una institución civil: el municipio romano (p. 40), que guarda una estrecha vinculación con la noción de comunidad. La raíz del término municipium es la misma que está presente en la idea de comunidad, tal como fuera cuidadosamente estudiada por Roberto Esposito en su libro Communitas. Se trata del munus, entendido como una pérdida, deuda u obligación (2003, p. 28). Los municipes serían, así, aquellos que asumen la deuda (munus capessere) y, en consecuencia, quedan mancomunados por la falta de asociación. De esta manera, podemos contrastar las formas en que Sarmiento y Sarquís procesan la carencia de asociación: si en el caso del primero esta deriva en una reivindicación del municipio, en el segundo adopta la forma de la philia. Pero en ambos la comunidad es invocada por un debilitamiento de los lazos asociativos.

Sin embargo, la noción de philia que campea en la película de Sarquís enseguida se abre a otros sentidos, como la conciliación y la negación del conflicto. En la reunión imposible entre Rosas, Quiroga y Alberdi que tiene lugar al comienzo del relato, la amistad deviene un mecanismo neutralizador de las diferencias que fue detectado por Alejandra Laera, para quien el anacronismo, lejos de ser un recurso estético, sería un escamoteo del conflicto que obedece a las exigencias ideológicas de la película: Sarquís dirime la polémica ideológica y política en una conversación de sobremesa (Laera, 1995, p. 74).

Dicho escamoteo se corresponde, por otra parte, con la noción de pueblo que plantea el filme. Según Quiroga, antes de pacificar el país "debemos explorar a fondo el sentimiento y parecer de los pueblos, es justo que ellos decidan con plena libertad". Esto implica una clara divergencia con respecto a Favio en lo que atañe no solo a la construcción del pueblo, sino también a los conceptos de comunidad y mito. Mientras que, en Juan Moreira, la comunidad se constituye como una búsqueda problemática del pueblo que falta, en Facundo. La sombra del Tigre, en cambio, el pueblo es tomado como un dato del ser común: Sarquís supone que existe una voluntad popular plenamente constituida y que el caudillo debe saber escucharla. La única pregunta relevante para él es cómo respetar la voluntad de los representados, dando por sentado que tal voluntad existe (por eso, la insistencia en la demanda constitucional a lo largo del filme). Pero esta asunción se basa en una concepción del pueblo que borra el conflicto ya que lo entiende solo como populus (la comunidad como un todo) y no en su ambigüedad populus/plebs (es decir, la tensión inerradicable entre la comunidad como un todo y la parcialidad que se identifica a sí misma con la comunidad como un todo).

De ahí que el mito en la película de Sarquís no sea la prefiguración de un pueblo que vendrá, como en Juan Moreira, sino el mito de un pueblo pasado que se corresponde con lo que Esposito entiende como el pliegue 
mitológico de la comunidad o la tendencia a buscar una esencia originaria que permita reducir lo común a lo propio, un sujeto común (Esposito, 2003, pp. 44-45). Esta operación aproxima a Sarquís al Favio de la década de 1990 y su evocación nostálgica del pueblo en filmes como Gatica, el mono (1993) y, sobre todo, Perón: sinfonía de un sentimiento (1999). Pero si se compara con el Favio de los años setenta, la relación es más bien de oposición.

Frente a la mitologización de la figura de Moreira que propone Favio, Sarquís apunta a una desmitificación de Facundo. El propio Quiroga lo sugiere cuando le dice a Santos Ortiz: "No invoque mi leyenda. Soy un hombre de carne y hueso". Esta operación es desmenuzada por Laera, que la caracteriza como una "desmitificación tramposa" por basarse en una falsa oposición y una reconstrucción parcial de los hechos: al borrar la actuación del caudillo en las montoneras del interior, Sarquís toma una parte del libro y le impone un signo ideológico distinto (1995, p. 74). Se trata de una operación típicamente revisionista de inversión desmitificadora de la dicotomía civilización/barbarie. Esta supuesta desmitificación se manifiesta de manera palmaria en dos incidentes que rodean la muerte de Quiroga. Por un lado, Sarquís exagera hasta la caricatura la lectura borgeana del episodio de Barranca-Yaco y la salida de Quiroga de la galera. Por otro, introduce un grupo de soldados federales con su vestimenta típica de la época, para justificar una acción armada que nunca existió. La muerte es -como apunta Laera- una fatalidad a la que el héroe no debe resistirse (1995, p. 76).

Pero hay otra muerte tomada del texto de Sarmiento que conecta a la película de Sarquís con la de Favio, a la vez que evidencia el lugar fallado de los modelos comunitarios que ambas obras postulan. Es la muerte del postillón que acompaña a Facundo en el degüello.

El hecho adquiere densidad porque en el filme este personaje aparece destacado cuando Quiroga le pide que cante para él e, inclinado por el afecto, lo contrata como ayudante de postillón. Y esto nos devuelve a un pasaje de Facundo que emerge con las tintas recargadas: "Los pueblos, en su infancia, son unos niños que nada prevén, que nada conocen, y es preciso que los hombres de alta previsión y de alta comprensión les sirvan de padre" (Sarmiento, 2006, p. 145).

En este punto de flexión, el modelo ético de la philia revela su potencial mortífero, en tanto lleva dentro de sí el filicidio. Y si los pueblos son como niños, el filicidio deviene genocidio (el postillón de Sarquís es reprendido por Santos Ortiz cuando dice que su país es Jujuy). Al igual que en la película de Favio, la muerte del filius (ya sea en su acepción de hijo, según el vocablo latino, o amigo, según la raíz griega presente en philios) figura la matanza del pueblo.

Desde este punto de vista, resulta casi inevitable pensar en Sarmiento como un protopadre de la cultura argentina y, simultáneamente, como un filicida, a partir del destino trágico de su hijo y de las autofiguraciones que pueden leerse en La vida de Dominguito (1963)7.

Hugo Vezzetti lee esta recurrencia de la muerte de los niños en la literatura argentina como un eco del niño muerto imaginario, fruto de la fecundación de la patria virgen por un ego europeo (1985, p. 13). En una carta a su amigo José Posse (citada por Vezzetti), Sarmiento proclama: “Te diré que si me dejan le haré a la historia americana un hijo" (1985, p. 96). El pueblo argentino, como Dominguito, sería el fruto de esta fecundación. Ese es el niño muerto, cuerpo fantasma del niño no nacido. En palabras de María Moreno (2005), "no hay cuerpo argentino esencial, pero hay cuerpos sustraídos a su descanso final". En ese sentido, los fantasmas de Juancito 
y el postillón viven en comunidad con el cuerpo desorganizado de Moreira, con el General sin manos y con el General Quiroga, enterrado de pie en la Recoleta.

Notas

1. Este concepto surge en la obra de Ernesto Laclau de la necesidad de nombrar un objeto imposible y necesario a la vez. Para él, la construcción política del pueblo es, esencialmente, catacrética (Laclau, 2005, p. 96). La identificación con un significante vacío, que represente una cadena equivalencial, sería la condición sine qua non de la emergencia de un pueblo. Por eso, el significante vacío es más que la imagen de una totalidad preexistente: es lo que constituye esa totalidad y a la vez la representa (2005, pp. 204-205).

2. Siguiendo a Gilles Deleuze y Felix Guattari, el Cuerpo sin Órganos puede definirse como un conjunto de prácticas para desprenderse del cuerpo. La estrategia supone dos fases: la primera para fabricar el Cuerpo sin Órganos y la segunda para hacer que las intensidades circulen en él. No obstante, aclaran Deleuze y Guattari, al Cuerpo sin Órganos no hay quien lo consiga, ya que es siempre un límite al que nunca se acaba de acceder (2002, p. 156).

3. El sketch se encuentra disponible en línea en: https://www.youtube.com/watch?v=wEROXaw2UX8.

4. Tampoco escapa a este mecanismo la representación de Moreira en La historia oficial (Puenzo, 1985), en la que el gay del curso interpreta a Vicenta. En este punto, no debe confundirse el tema de la película con su politicidad. Es indudable que, con 1.700 .000 espectadores, la película de Puenzo alcanzó un alto grado de masividad. Pero si entendemos la política, siguiendo a Jacques Rancière, como la irrupción del desacuerdo (1996, p. 43), no puede afirmarse que el filme exhiba un grado elevado de politicidad ya que, como afirma Gonzalo Aguilar, al no incorporar un punto de vista que reivindique la violencia surgida de las organizaciones armadas, la película contribuyó a la creación de un efecto de clausura sobre el relato de los años setenta y una interdicción tácita sobre la defensa de lo hecho por la guerrilla (2012, p. 116).

5. A diferencia de la comunidad, el concepto de sociedad civil -tal como lo conciben los padres fundadores de la sociología clásica- supone un sistema de dependencia multilateral entre personas particulares que entablan entre sí relaciones económicas, culturales y jurídicas, con independencia de la dimensión política (Álvaro, 2013, p. 168).

6. Si bien escapa a los objetivos de este trabajo, es interesante notar -en sintonía con las relaciones entre Sarmiento y el socialismo estudiadas por Horacio Tarcus (2013)- la proximidad temporal entre Facundo y textos como las "Cartas cruzadas en 1843" o las "Glosas críticas al artículo “El rey de Prusia y la reforma social por un prusiano", en los que el joven Marx (1982) introduce por primera vez en su obra la preocupación comunitaria.

7. Dominguito murió a la edad de veintiún años. Es decir, la misma edad que tenía el soldado Carrasco en 1994. El dato no es arbitrario si consideramos que en Argentina la mayoría de edad se fijó a los veintidós años hasta 1968, momento en que pasó a ser a los veintiuno. De este modo, Dominguito y Carrasco mueren, respectivamente, en el límite y el umbral de la niñez, como señalando una imposibilidad de transgredir el pasaje a la adultez.

Bibliografía 
Aguilar, G. (2011). “Juan Moreira de Leonardo Favio. En busca del pueblo”. La fuga. Disponible en: http://www.lafuga.cl/juan-moreira-de-leonardo-favio/307.

(2012a). "En los confines de la racionalidad: Leonardo Favio y las fabulaciones de los bandidos y las bestias". En W. Bongers (ed.), Prismas del cine latinoamericano (pp. 145-166). Santiago de Chile: Cuarto Propio. . (2012b). "La historia más allá del cine (el documental argentino y el retorno de la democracia)".

Archivos de la Filmoteca, $\mathrm{n}^{\circ} 70,107-117$.

Aguilar, G. y Oubiña, D. (1993). El cine de Leonardo Favio. Buenos Aires: Nuevo Extremo.

Álvaro, D. (2013). “El concepto moderno de comunidad”. Sociedad, n³2, 159-175.

Anderson, B. (2011). Comunidades imaginadas. Reflexiones sobre el origen y la difusión del nacionalismo. Buenos Aires: Fondo de Cultura Económica.

Barthélelemy, J-J. (1847). Viaje del joven Anacarsis a la Grecia. Madrid: La llustración.

Carrizo, F. (1903). "La muerte de Juan Moreira”. Caras y Caretas, nº 235, 4 de abril.

Cuman, S. y Sierra, V. (2005). “José Pablo Feinmann”. En AAVV, Guionistas por guionistas (111-124). Buenos Aires: Altamira.

Davobe, J. P. (2010). "Eduardo Gutiérrez: narrativa de bandidos y novela popular argentina”. En A. Laera (dir.), El brote de los géneros,. 3 de Historia crítica de la literatura argentina (dir. N. Jitrik). Buenos Aires: Emecé.

Deleuze, G. y Guattari, F. (2002). Mil mesetas. Capitalismo y esquizofrenia. Valencia, Pre- Textos.

Deleuze, G. (2005). La imagen-tiempo. Estudios sobre cine 2. Buenos Aires: Paidós.

Esposito, R. (2003). Communitas. Origen y destino de la comunidad. Buenos Aires: Amorrortu.

Favio, L., Hurovich, T. y Sires, J. (Productores) y Favio, L. (Director). (1973). Juan Moreira [Película]. Argentina: Centauro Films.

Gutiérrez, E. (1999). Juan Moreira. Buenos Aires: Perfil.

Laclau, E. (2005). La razón populista. Buenos Aires: Fondo de Cultura Económica.

Laera, A. (1995). "La vacilación entre la historia y la leyenda: sobre Facundo. La sombra del Tigre de Nicolás Sarquís". Espacios de crítica y producción, 17, noviembre-diciembre, 74-76.

Ludmer, J. (1998). "Héroes hispanoamericanos de la violencia popular: construcción y trayectorias (para una historia de los criminales populares en América Latina)". En Actas del XII Congreso de la Asociación Internacional de Hispanistas, Birmingham vol. 7, 1-14. 

(2011). El cuerpo del delito. Un manual. Buenos Aires: Eterna Cadencia.

Marx, K. (1982). Escritos de juventud. México: Fondo de Cultura Económica.

Moreno, M. (2005). "Facundo (una -caprichosa- lectura de los cuerpos argentinos y sus fundaciones mitológicas)". Página 12, 18 de febrero.

Nancy, J-L. (2000). La comunidad inoperante. Santiago de Chile: LOM Ediciones/ Universidad ARCIS.

Neifert, A. (2012). Rosas y su época en el cine argentino. Buenos Aires: Ediciones Fabro.

Péron, J. D. (1971). Conducción política. Buenos Aires: Freeland.

Piñeyro, M. (Productor) y Puenzo, L. (Director). (1985). La historia oficial [Película]. Argentina: Historias Cinematográficas Cinemanía y Progress Communications.

Prieto, A. (2006). El discurso criollista en la formación de la Argentina moderna. Buenos Aires: Siglo XXI.

Rancière, J. (1996). El desacuerdo. Política y filosofía, Buenos Aires: Nueva Visión.

Sarmiento, D. F. (1963). La vida de Dominguito. Buenos Aires: Ediciones Culturales Argentinas. (2006). Facundo. Buenos Aires: Colihue.

Sarquís, N. y Torre Nilsson, L. (Productores) y Sarquís, N. (Director). (1977). La muerte de Sebastián Arache y su pobre entierro [Película]. Argentina: Nicolás Sarquís.

Sarquís, S. (Productor) y Sarquís, N. (Director). (1995). Facundo. La sombra del tigre [Película]. Argentina: Argentina Televisora Color, Fundación Argentina para el Desarrollo de Temas Audiovisuales, Instituto Nacional de Cine y Artes Audiovisuales, Subsecretaría de Cultura de la Nación.

Tarcus, H. (2013). "Sarmiento y el socialismo". En G. Batticuore y A. Laera (comps.), Sarmiento en intersección: literatura, cultura y política (pp. 46-69). Buenos Aires: Centro Cultural Rector Ricardo Rojas - Universidad de Buenos Aires.

Vassuk, V. (Productor) y Favio, L. (Director). (1999). Perón, sinfonía del sentimiento [Película]. Argentina: Fundación Confederal y 101 Producciones.

Vezzetti, H. (1985). La locura en la Argentina. Buenos Aires: Paidós.

Zayas de Lima, P. (2010). El universo mítico de los argentinos en escena. Buenos Aires: Instituto Nacional del Teatro.

Abstract: 
This article addresses two film transpositions of texts from the Argentine literature of the 19th Century: Juan Moreira (Leonardo Favio, 1973) and Facundo. La sombra del tigre (Nicolás Sarquís, 1995), both produced in the last third of the 20th century. Through the inscription of both films in their respective historic and political contexts, I aim to contrast the community models that each film implies, as well as the corresponding figurations of the concepts of people and myth.

Key words:

people - community - myth - argentine literature - argentine cinema.

Resumo:

Este trabalho aborda duas transcrições de textos da literatura argentina do século XIX que foram adaptados ao cinema no último terço do século XX: Juan Moreira (Leonardo Favio, 1973), Facundo e La sombra del tigre (Nicolás Sarquís, 1995). A partir da inscrição de ambos os filmes em seus respectivos contextos históricopolítico, pretende-se contrastar os modelos comunitários que emanam de cada uma das obras, bem como as figurações dos conceitos de povo e mito que elas propõem.

Palavras chave:

povo - comunidade - mito - literatura argentina - cinema argentino.

Pueblo, comunidad y mito en Juan Moreira de Leonardo Favio y en Facundo. La sombra del Tigre de Nicolás Sarquís fue publicado de la página 77 a página88 en Cuadernos del Centro de Estudios de Diseño y Comunicación $\mathrm{N}^{\circ} 61$ 